Japanese Psychological Research

1981, Vol. 23, No. 3, 131-139

\title{
Preference regions on preference scales
}

\author{
KAORU AZUMI \\ Department of Psychology, Keio University, Mita, Minato-ku, Tokyo 108
}

The aim of this study is to investigate the choice strategy under uncertainty. Female subjects were asked to choose their hypothetical marriage partners among 30 alternatives. Results were analyzed by comparing the positions of the accepted and the rejected alternatives on the preference ordinal scales. The preference scale may be divided into at least two regions; the positive and the negative regions. The subjects had a tendency to reject an alternative when more than one of $i t s$ aspects were in the negative region, and to accept an alternative when all of its aspects were in the positive region.

Key words: choice behavior, choice strategies, multi-aspect alternatives, rank order of preferences, marriage partner selections.

People are often faced with making a choice among several alternatives. In most of the cases, those alternatives consist of many aspects. There are many theories of choice, where descriptive or normative models of choice strategies are mentioned. For example, the lexicographic rule (see e.g., Coombs, 1964; Fishburn, 1968; MacCrimmon, 1968 etc.), the additive weighting model (see e.g., Churchman, Ackoff, \& Arnoff, 1957; Terry, 1963; Fishburn, 1964 etc.), the satisficing rule (Simon, 1955, 1957), and the nonmetric scaling model (see MacCrimmon, 1968), and so on.

The lexicographic rule assumes the following choice strategy: The subject compares the alternatives on one aspect which is the most important to that subject. If an alternative has a higher aspect value than any other alternative, it is chosen and the choice process ends. If no single alternative is predominant in this dominant aspect, then the non-maximal alternatives (that is, those with less than the common maximum value) are dropped from further consideration. The remain-

1 The author is indebted to Professor Tarow Indow of University of California, Irvine for his advice throughout the research and Professor Takashi Ogawa of Keio University for his critical reading of the manuscript and valuable comments. ing alternatives are then compared with regard to the next most important aspect. The process continues in this lexicographic fashion either until a single alternative is chosen or until all aspects have been considered.

In the additive weighting model, the relative importance of each aspect is also considered. The choice strategy proposed by this model is as follows: If the decision maker can choose a numerical measure of importance, then he may weight each aspect value by this measure to get a weighted average of the contribution of each alternative. He will then select the alternative with the highest weighted average.

The satisficing rule assumes that the decision maker will supply the minimal aspect value he will accept, and accept the alternatives that satisfy the minimal requirement. And successively he will reduce the feasible set. Alternatively, if none of the alternatives met the specified requirements, the requirements could be changed so as to increase the feasible set.

Finally, the non-metric scaling model assumes the following choice strategy: In this model, not all of the aspects are examined. For example, the 3 (or more generally k) most important aspects are considered while the remaining $n-3$ (or $n-k$ ) aspects are disregarded in the choice 
process. And each alternative is placed in the 3 (or $k$ ) dimensional space. If this spatial representation does in fact characterize each alternative, it may also determine the decision maker's most preferred alternatives. Suppose we specify an ideal object, one with the most preferred values in each aspect. Then, after placing this object in the appropriate place in the spatial representation, we can determine the distance of each of the other alternatives from this ideal. The alternative that is closest to the ideal object would then be chosen.

There are many other models proposed in the fields of economics and psychology. In contrast to the many theoretical works of choice strategies, however, there have been relatively few empirical studies in which the models were tested. As Tversky (1970, 1972) has pointed out, the scarcity of data is due to the difficulties involved in controlling the experiment appropriately and obtaining adequate estimates of choice probabilities.

In the previous study (Azumi, 1976), each female subject was asked to choose one man as her hypothetical marriage partner among three alternatives. By using the rank order of attractiveness of aspects as an aid, it has been found that, in most cases, the chosen alternatives had the greatest number of aspects with the highest ranks. Hence, it seems advisable to use the rank order of attractiveness for the study of choice strategies.

In this study, the choice strategies that the subjects use to choose among alternatives were examined empirically. For this purpose, the choice results were compared with the rank order of attractiveness of each aspect.

\section{Experiment}

In the experiment, female subjects were presented with a photograph and a short description of a male person, and they were asked whether they would like to date with the described person with marriage in mind. The experiment consisted of two stages: one for obtaining the ordinal preference scales as basic data, and the other for choice.

\section{Method}

Subjects. The subjects were 11 female students of Keio University, aged from 19 to 25 years old. They were all unmarried. The same 11 subjects participated in stage 1 and 2 of the experiment.

Procedure in stage 1. This stage was used to determine the ordinal preference scales. The subject was presented with cards, on which some features of men were written. She was asked to place those cards in the order of attractiveness as her marriage partner's features.

In the experiment, 11 aspects and photographs were used as characteristics of hypothetical marriage partners. These 11 aspects on a man were as follows; a man's occupation, income, age, school, family, physical build, father's occupation, place of residence, hobby, personal character, and expectations of the future wife. In each of the 11 aspects, there were 10 to 20 items. For example, in the aspect "occupation", there were items such as "doctor", "teacher", "farmer", "bank clerk", and so on, and in the aspect "hobby", there were items such as "skiing", "tennis", "mountain climbing", etc. All the items used in stage 1 are listed in Table 1.

Each item was written on each card, and the subject was asked to rank items in the same aspect. Thirty photographs (which were obtained from college yearbooks) were also ranked in the order of attractiveness as her marriage partner. In the ranking of cards, two cards were allowed to be given the same rank. In addition to this intra-aspect ordering, inter-aspect ordering was also obtained; i.e., the subject was asked to place cards of aspect names in the order of importance when she chose her marriage partner. 
Table 1

Items used in stage 1 of the experiment. Items in the parentheses are common to all other items; e.g. "(serious-minded) lives for job, lives for family, etc." means "serious-minded and lives for job, serious-minded and lives for family, etc."

\begin{tabular}{|c|c|}
\hline Occupation & $\begin{array}{l}\text { office-man, trade company employee, doctor, lecturer, teacher, architect, } \\
\text { civil engineer, lawyer, pressman, wine merchant, manager of a restaurant, } \\
\text { policeman, pilot, painter,owner of a private preparatory school, farmer, } \\
\text { diplomat, taxi driver, bank clerk. }\end{array}$ \\
\hline Income & $\begin{array}{l}70000 ; 100000 ; 120000 ; 150000 ; 180000 ; 210000 ; 300000 ; 500000 ; \\
800000 ; 1000000 \text { (yen per month). }\end{array}$ \\
\hline Age & $24,25,26,27,28,29,30,32,34$ (years old). \\
\hline Place of residence & $\begin{array}{l}\text { Tokyo, Chiba, Osaka, Kyoto, Fukuoka, Miyazaki, Sendai, Niigata, Sap- } \\
\text { poro, Kobe, Kochi, Yokohama, U.S.A., Brazil, England, India. }\end{array}$ \\
\hline Father's occupation & $\begin{array}{l}\text { government employee, banker, bookseller, wine merchant, office-worker, } \\
\text { policeman, doctor, businessman, diplomat, judge, university professor, } \\
\text { teacher, landowner, guard, carpenter, farmer, fisherman, no occupation. }\end{array}$ \\
\hline Physical build & $\begin{array}{l}160(\mathrm{~cm} \text { in height }) / 47(\mathrm{~kg} \text { in weight }), 162 / 56,160 / 65,160 / 70,162 / 75,173 / 60, \\
175 / 60,178 / 63,180 / 65,170 / 70,183 / 90,175 / 70,180 / 80,165 / 60,168 / 65\end{array}$ \\
\hline Personal character & $\begin{array}{l}\text { (cheerful and sociable) lives for family, lives to enjoy his hobbies, always } \\
\text { does his best to develop his abilities, observes moderation; (serious- } \\
\text { minded) lives for job, lives for family, lives to enjoy his hobbies, always } \\
\text { does his best to develop his abilities; (shy and quiet) lives for family, } \\
\text { lives to enjoy his hobbies, observes moderation, always does his best to } \\
\text { develop his abilities; (cheerful but slightly nervous) lives to enjoy his } \\
\text { hobbies, lives for job, always does his best to develop his abilities; (a } \\
\text { leader and reliable) lives for job, lives for family, always does his best } \\
\text { to develop his abilities. }\end{array}$ \\
\hline Hobby & $\begin{array}{l}\text { skiing, tennis, golf, fishing, travelling, driving, listening to music, movie- } \\
\text { going, playing music, photography, mountain climbing, Go and Shogi, } \\
\text { Sado, swimming, gardening, rugby, painting, yachting, no hobbies. }\end{array}$ \\
\hline Family & $\begin{array}{l}\text { (parents and) no brothers, } 3 \text { brothers } \& 1 \text { sister, } 1 \text { brother, } 2 \text { brothers, } 1 \\
\text { sister, no parents and } 3 \text { brothers, (a mother and) no brothers, } 1 \text { brother } \& \\
1 \text { sister, (a father and) no brothers, } 2 \text { sisters, } 1 \text { brother } \& 1 \text { sister. }\end{array}$ \\
\hline $\begin{array}{l}\text { Expectations of his } \\
\text { future wife }\end{array}$ & $\begin{array}{l}\text { (living with his parents and) being a good housewife, supporting hus- } \\
\text { band's job; (living with his parents in future and) being a good housewife, } \\
\text { sharing household expenses, supporting husband's job; (living apart from } \\
\text { his parents and) being a good housewife, sharing household expenses, if } \\
\text { she pleases, continuing her job to develop her ability. }\end{array}$ \\
\hline School & $\begin{array}{l}\text { high school; professional school; Doshisha, Hokkaido, Hosei, Kanagawa, } \\
\text { Tokai, Keio,Kochi, Nihon, Tokyo, Tokyo Univ. of Arts (University); } \\
\text { (graduate school at) Rikkyo, Tokyo, Tokyo Institute of Technology, Tokyo } \\
\text { Metropolitan (University); (left school without finishing the whole course } \\
\text { at) Hosei, Doshisha, Keio, Yokohama National (University). }\end{array}$ \\
\hline
\end{tabular}

Subjects were tested individually. It took about 30 to 40 minutes for the subject to complete the ranking tasks.

Materials in stage 2. The descriptions of
30 hypothetical male persons in terms of 11 aspects listed in Table 1 were constructed. In making each alternative description, items were chosen at random, 
so that some items were used in two or three alternatives. An example of the alternative is the following.

Occupation bank clerk.

Income $\quad 180000$ yen per month.

Age

School

Family

Physical build

Father's occupation

Place of residence

Hobby

Personal character

Expectations of his future wife 29 years old. graduated from Keio University. parents and a younger sister.

$175 \mathrm{~cm}$ in height and $70 \mathrm{~kg}$ in weight. banker.

Yokohama.

fishing. cheerful and sociable; living to enjoy his hobbies.

living with his parents in future and being a good housewife.

Procedure in stage 2. The subject was presented with descriptions of 30 men one by one, and was asked whether she would like to date with the described person with marriage in mind; first, the subject was given a photograph and was asked if she would like to date with the man. She could choose one of three possible ways of answering. That is, if she liked the photograph so much as to date with him without getting any other information about him, she could choose the man immediately, while if she disliked the photograph so much as to reject all the other information about him, she could reject him immediately. The third possibility was to put off her decision until she got more information about him. If she wanted more information about him, the information about one aspect was given to her. After that, she was asked to choose among the same three ways of answering as before. The trial continued in this manner until she decided on a date. Whether she accepted or rejected the alternative, the next trial was allowed and she was presented the next alternative.

The order of presentation of aspects was determined by the importance of aspects that the subject indicated previously, so that the presentation order was different from one subject to another. Of half of the 30 males, the aspects were presented beginning with the most important one. For the remainder, the order was reversed. But the photographs were always presented first. All information was presented orally by the experimenter except for the photographs. The subjects could choose as many men as they pleased, and they were tested individually. There were no time restrictions throughout the experiment. It took the subjects about one hour to finish stage 2. The subjects participated in stage 2 about two weeks after stage 1 .

\section{Results}

Results were analyzed by comparing the positions of the accepted and the rejected alternatives on the preference ordinal scales. Since four of 11 subjects rejected all alternatives, only the remaining seven subjects' data were analyzed. Figure $1-a, b$ show the results of two of the seven subjects.

In these figures, items of each aspect were placed from left to right, from the most attractive to the least attractive items for that subject. Each number denotes an alternative (No. 1 to No. 30). The symbol surrounding each number indicates one of the following four states. A double circle indicates that the alternative was accepted at that position; an open circle, that it was accepted later; a rectangle, that it was rejected later; and a cross, that it was rejected at that position. The aspects were placed from top to bottom, in the order of importance. As noted before, the presentation of aspects had two orders: one beginning with the most important aspect and the other beginning with the least important one. For alter- 


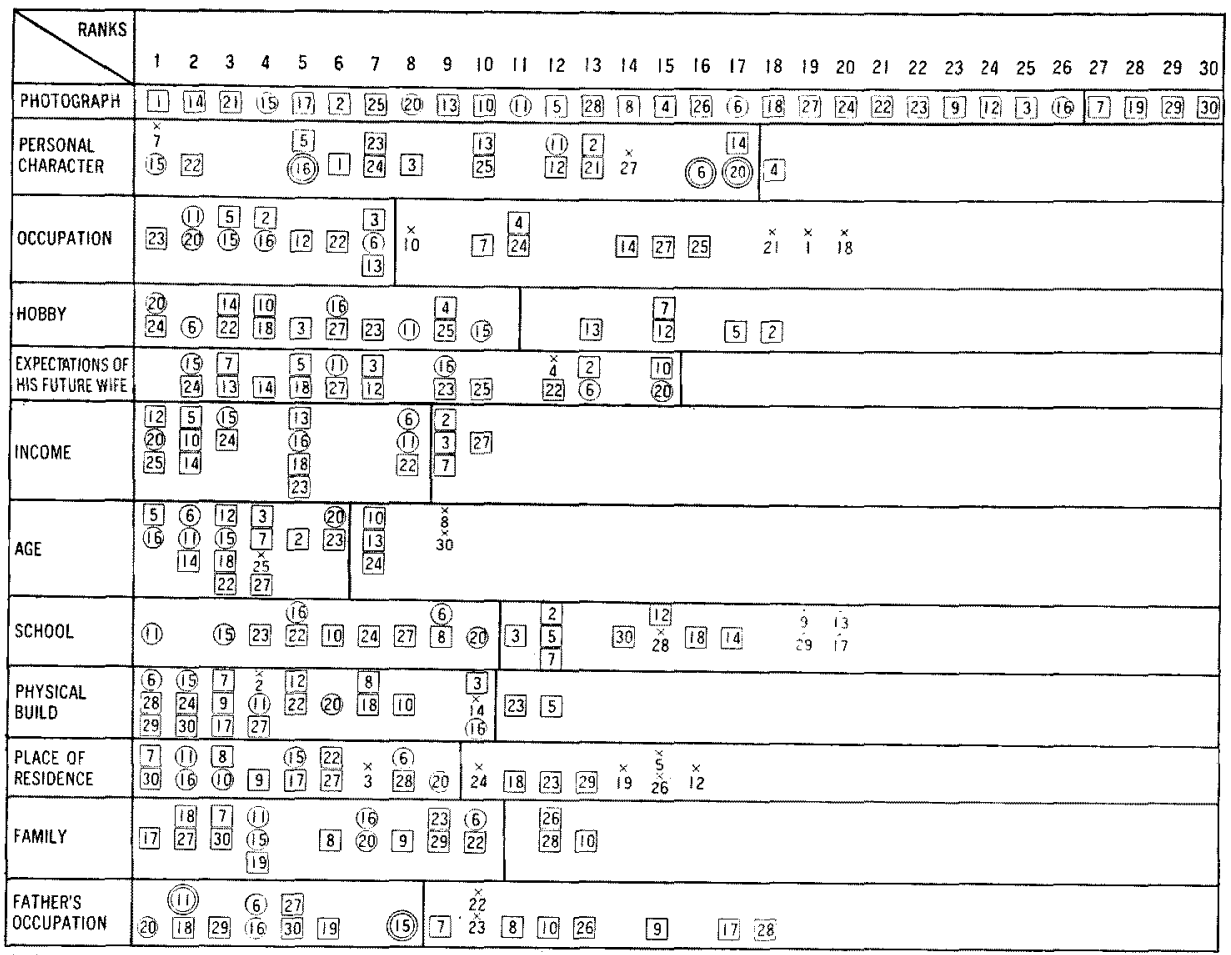

(a)

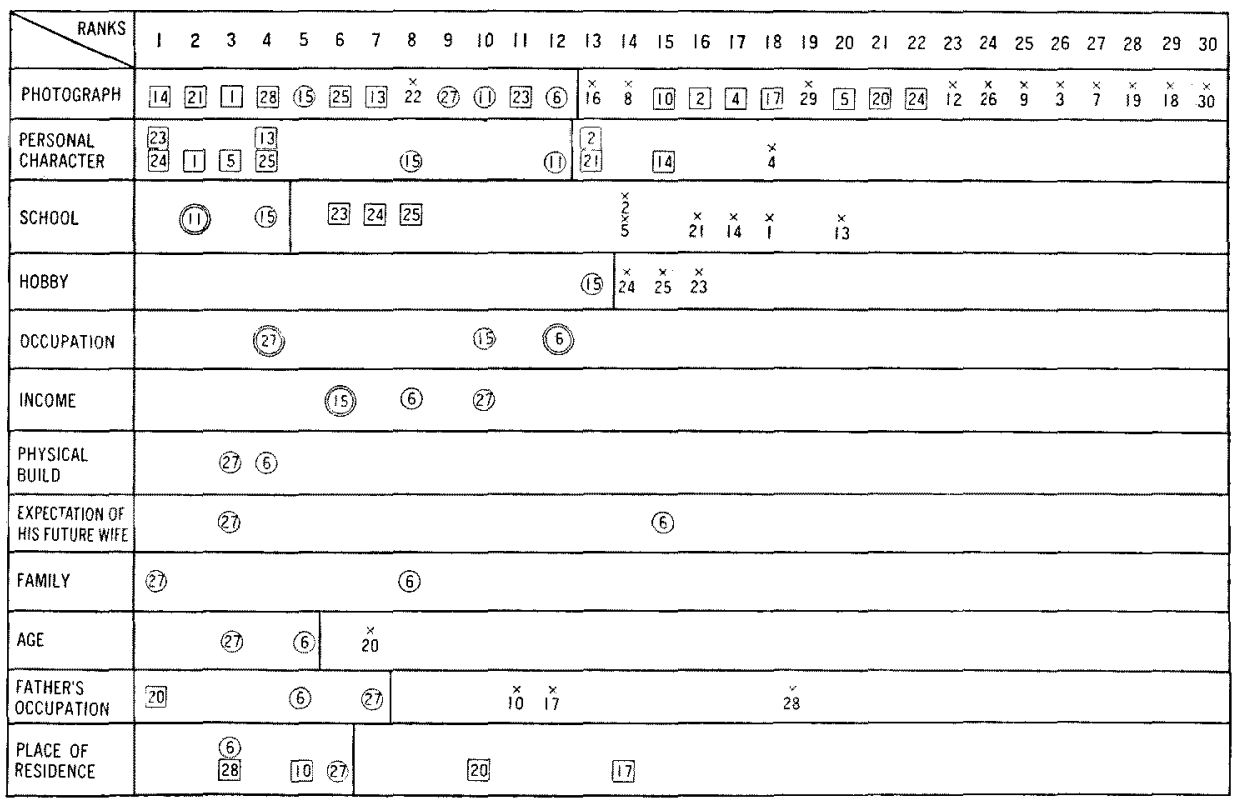

(b)

Fig. 1. The results of one of seven subjects. Each row represents the ordinal preference scale, representing left to right the most preferable to the least preferable. Numbers denote the alternatives. Aspects are placed top to bottom, in the order of importance. (): the alternative was accepted at that position; $O$ : accepted later; $\square:$ rejected later; $X:$ rejected at that position. 
natives No. 1 to 5,11 to 15 , and 21 to 25 , aspects were presented in the former order, and for the remainder, the reverse order was applied. In Fig. 1-a, for example, in the alternative No. 1 case, a photograph was presented first, and personal character, occupation, hobby, etc. were presented in that order. In the case of the alternative No. 6, a photograph was presented first, and father's occupation, family, place of residence, etc. were presented in that order. There may be more than one number in the same position on the scale, since ties were allowed and some items were used in more than one alternative.

In Fig. 1, the preference scale of each aspect may be partitioned into two regions; the left portion which contains circles (called the "positive region"), and the right portion with no circles but containing rectangles and crosses (called the "negative region"). In the figure, vertical lines show boudary lines of the positive and the negative regions.

In examining the loci (the change of ordinal preference of successively presented aspects) of the rejected alternatives, it seems that many of them are located in the negative regions more than once. Figure 2 shows the number of deviations from the positive regions, and crosses indicate the rejection of the alternatives.

For example, sb. A rejected 1 alternative after 2 aspects were presented, and one of them was located in the negative region; moreover, she rejected 3 alternatives with 5 presented aspects each, and 3 of 5 aspects were located in the negative region. As is seen in the figure, it can be said that the subjects rejected an alternative when more than one of its aspects deviated from the positive region. Figure 2 shows that the alternatives rejected with no deviations are only 9 out of 183 of seven subjects' results.

In Fig. 2, circles represent the alternatives which were accepted at that aspect presentation stage. That is, sb. A ac- cepted 3 alternatives after examining 10 , 11 , or 12 aspects. The subjects seemed to examine more aspects in accepting the alternatives rather than in rejecting them. Moreover, five out of seven subjects (i.e., sb. A, B, C, F, G) took into account almost all aspects before accepting an alternative, but the remaining two subjects (i.e., sb. D, E) attended to only 5 or 6 aspects.

Examining Fig. 1-a, b again, we find some scales where many crosses gather in the lowest portion (see for example, " photograph", "school", "hobby", and "father's occupation" in Fig. 1-b). The negative region may be partitioned into two regions again; i.e., the left hand portion of the negative region which contains rectangles and crosses (called the

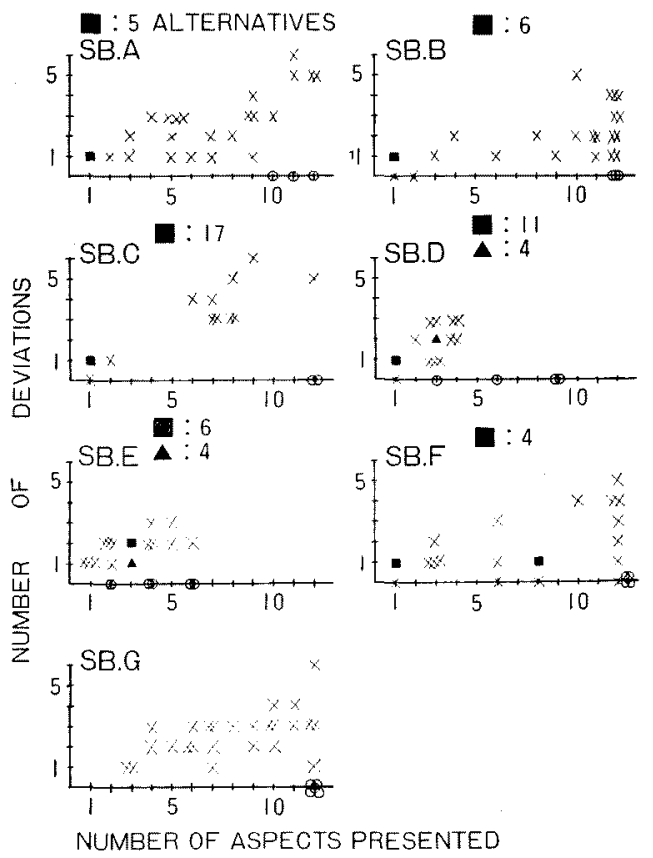

Fig. 2. The number of deviations from the positive regions before the alternative was rejected. Abscissa represent the number of aspects presented. Crosses indicate rejections. Circles denote that the alternatives were accepted after that number of aspects were presented. In the figure, when more than three crosses gather at the same position, and $\Delta$ were used to stand for crosses. 
"negative region", again), and the right hand portion which contains only crosses. The latter region may be called the "repulsive region". The intuitive ground for assuming the repulsive region is as follows. In choice situations, people may at once reject an alternative with a very unfavorable or disadvantageous aspect, regardless of the other favorable features. For example, a young girl who wants to be a career woman may at once say " no" to a courting man who expects his future wife to be a good housewife. A tall girl may reject a man who is shorter than she regardless of the other features.

As shown in Fig. 2, some alternatives were rejected with only 1 or 2 deviations from the positive regions, but the others were rejected with more than 3 deviations. It seems likely that the subjects considered the relative importance of the aspects. It seems plausible to assume that the subjects will reject the alternative with a relatively small number of deviated aspects when aspects are presented beginning with the most important one. Thus, if more than one important aspect is located in the negative region, then the subjects will reject the alternative. On the other hand, when aspects are presented in the reverse order, the subjects may put off their rejection of the alternative until further important aspects are presented.

Figure 3 shows the deviation patterns

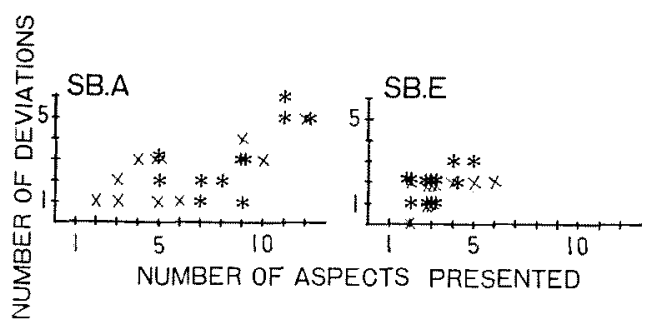

Fig. 3. The number of deviations from the positive regions in comparing two aspect presentation conditions. $\quad x:$ rejections of the alternatives in the IAF condition. *: rejections of the alternatives in the UAF conditions. Entries at the point $(1,1)$ were omitted. of the "important-aspect-first" alternatives (called the IAF condition), and the " unimportant-aspect-first" alternatives (called the UAF condition). The $\times$ 's indicate the rejections of alternatives under the IAF condition. The *'s indicate the rejections of alternatives under the UAF condition. In the figure, in sb. A case, the above assumption held true and the subject seems to have considered the relative importance of the aspects; she examined more aspects (and had a greater number of deviations) under the UAF conditions. But in sb. E case, these differences were not observed. That is, the subject examined relatively few and almost the same number of aspects in either case. For sb. E, the relative importance of the aspects may have had little or no effect in making decisions. Five out of seven subjects showed sb. A type deviation patterns (but they examined more aspects than sb. A in the IAF condition), and the remaining two subjects showed sb. E type patterns.

\section{Discussion}

The present results may be summarized as follows:

1) When examining the choice results on ordinal preference scales, scales can be divided into two regions: one, where all the aspects of accepted alternatives are located (called the positive region) and the other, where the aspects of the rejected alternatives are located (called the negative region).

2) In some of the negative regions, the repulsive regions may be defined. All the alternatives in the repulsive regions are rejected at that position.

3) Most of the rejected alternatives are located in the negative regions more than once.

4) The accepted alternatives seem to require much longer decision processes (by examining a greater number of aspects) than the rejected alternatives. 
Furthermore, five out of seven subjects examined almost all aspects to accept the alternatives.

5) The importance of each aspect seems to influence decision making on the part of some subjects.

All the aspects of the accepted alternatives are located in the positive regions, as stated above; hence, it seems rather natural to consider that items in the positive regions are relatively favorable or at least allowable as a marriage partner's features to that subject. On the other hand, the items in the negative regions can be considered as relatively unfavorable or disadvantageous features.

As summarized above, the subjects examined almost all aspects before they accepted an alternative. In doing so, the subjects seem to avoid the risk of accepting an alternative with an unfavorable aspect. In the lexicographic rule, it is assumed that the subject will choose the alternative with the most important and favorable aspect. In this case, however, the subject may take a risk of having an unfavorable or disadvantageous aspect. The present results show that the subjects are much more careful. As shown in Fig. 2, however, there are a few exceptional cases (in sb. D and E), where the subjects accepted the alternatives with 2 or 3 aspects alone.

As was mentioned above, an alternative was rejected before all the aspects were examined when more than one aspect was revealed to be unfavorable or disadvantageous. In many of the choice models, a positive, real-numbered utility function is assumed, which represents the degree of favorableness or utility of an aspect (or an alternative). Then, unfavorableness of an aspect (or an alternative) is represented by a small value (or nearly zero value) on the utility scale. Thus, the unfavorableness of one aspect can be compensated for by other favorable aspects. But the subjects of the present experiment rejected the alternatives when they met unfavorable aspects. Hence, the present results seem to show the necessity of assuming negative values of utility, as well. In the additive weighting model, all the weighted utility values of the aspects are summed up. But even if the weighting procedure and the estimations of utility values can be done well, still it is necessary to consider the unfavorableness of aspects.

In the results, 2 (or 3 ) preference regions and 1 (or 2) cut-off points were operationally determined. The subjects accepted the alternatives that satisfy standards (cut-offs) at all the aspects. In this sense, this strategy seems to resemble that of the satisficing rule. However, in the post-experimental interview, none of the subjects reported on the regions or the cut-offs. Perhaps they may simply make a favorable or unfavorable judgement concerning each aspect, and they may not judge whether or not each aspect satisfies the requirement as the satisficing rule assumes. But responses obtained show rather consistent standards.

It may also be the case that the subjects set up a kind of ideal object as the non-metric scaling model specifies (the subjects may or may not be aware of that ideal object). Then, items in the positive regions can be considered to be located within the limit of allowable distance from the ideal object, and items in the negative regions are located beyond the limit of allowable distance from the ideal. However, contrary to the non-metric scaling model's prediction, the subjects in this experiment accepted an alternative when all of its aspects were located within the limit, and rejected it when more than one of its aspects were located beyond the limit. Two of seven subjects could portray the alternatives in 5 or 6 dimensional space, but the remainder depicted the alternatives in almost 12 dimensional space. In the present study, the subjects could choose as many alternatives as they 
pleased, but when they must choose only one alternative, the non-metric scaling model predicts that the alternative which is the closest to the ideal will be chosen. With the present results alone, we cannot discuss the appropriateness of that prediction. But in choosing something or determining something, we usually undergo inner conflicts, because the choice of one alternative means losing the possibilities of getting the other favorable alternatives (see Indow, 1975). As Indow mentioned, choice and decision making are, in essence, conflict processes. However, in this study no such view is introduced. This is a subject for future investigation.

\section{References}

Azumi, K. 1976 On choice procedure. Unpublished master's thesis, Keio University. (In Japanese)

Churchman, C., Ackoff, R. L., \& Arnoff, E. L. 1957 Introduction to operations research. New York: Wiley.
Coombs, C. H. 1964 A theory of data. New York: Wiley.

Fishburn, P. C. 1964 Decision and value theory. New York: Wiley.

Fishburn, P. C. 1968 Utility theory. Management Science, 14, 335-378.

Indow, T. 1975 On choice probability. Behaviometrika, 2, 13-31.

MacCrimmon, K.R. 1968 Decision making among multiple-attribute alternatives: a survey and consolidated approach. Rand memorandum, RM-4823. Rand Corporation.

Simon, H. A. 1955 A behavioral model of rational choice. Quarterly Journal of Economics, 69, 99-118.

Simon, H. A. 1957 Models of man. New York: Wiley.

Terry, H. 1963 Comparative evaluation of performance using multiples criteria. Management Science, 9, 431-442.

Tversky, A. 1970 Individual decision making. In C. H. Coombs, R. M. Dawes, \& A. Tversky (Eds.), Mathematical psychology: An elementary introduction. New Jersey: Prentice-Hall.

Tversky, A. 1972 Elimination by aspects: a theory of choice. Psychological Review, 79, 281299.

(Received May 30, 1980; accepted July 4, 1981) 